\title{
Treatment of Bone Defects in War Wounds: Retrospective Study
}

\author{
Predrag Grubor ${ }^{1}$, Snjezana Milicevic ${ }^{2}$, Milan Grubor ${ }^{1}$, Luigi Meccariello \\ ${ }^{1}$ Clinic of Traumatology, University Hospital Clinical Center Banja Luka, Bosnia and Herzegovina \\ ${ }^{2}$ Urology Clinic, University Hospital Clinical Center Banja Luka, Bosnia and Herzegovina \\ ${ }^{3}$ Department of Medical and Surgical Sciences and Neuroscience, Section of Orthopedics and Traumatology, University of Siena, \\ University Hospital “Santa Maria alle Scotte”, Siena, Italy
}

Corresponding author: prof. Predrag Grubor, Md PhD. Clinic of Traumatology, University Hospital Clinical Center Banja Luka, Bosnia and Herzegovina E-mail:predraggrubor@gmail.com

\begin{abstract}
Introduction: Results of the treatment of open fractures primarily depend on the treatment of connected soft tissue injuries. Objective. The aim was to present the experience and methods gained during the treatment of diaphyseal bone defects as a consequence of gunshot fracture soft war trauma. Patients and Methods: The study consisted of 116 patients with the diaphyseal bone defect who were treated with the usage of primary and delayed autotransplantation of bones, transplants of the fibula and Ilizarov distraction osteogenesis. Results: The results of compensation of bone defect less than $4 \mathrm{~cm}$ and conducted by an early cortico-spongioplastics were as follows: good in 8 respondents (45\%), satisfactory in $6(34 \%)$ and poor in 4 respondents $(21 \%)$. In cases of delayed cortico-spongioplastics , the above mentioned results were: good in $36(41 \%)$ respondents, satisfactory in $24(34 \%)$ and poor in $16(25 \%)$ respondents. The results of compensation of bone defect greater than $4 \mathrm{~cm}$ with the usage of fibular transplant were as follows: good in 3 (38\%) respondents, satisfactory in 3 (38\%) and poor in 2 (24\%), and with the usage of using the Ilizarov method, the results were as follows: good in 8 (57\%) respondents, satisfactory in 3 (21.5\%) and poor in 3(21.5\%) respondents. Conclusion: The results showed that, in cases of compensation of bone defects less than $4 \mathrm{~cm}$, the advantage is given to the primary spongioplastics over the delayed one. In cases of compensation of bone defects greater than $4 \mathrm{~cm}$, the advantage is given to the Ilizarov distraction osteogenesis when compared to the fibular transplant.
\end{abstract}

Key word: bone defects; autotransplantation; transplants of the fibula and Ilizarov.

\section{INTRODUCTION}

War wounds caused by firearms, represent damage to the body, whose features are extensive destruction of the tissue, primary contamination with polymorphic bacterial flora and altered reactivity of the organism (1). War trauma injuries are usually injuries to the extremities (about 70\%), out of which about $40 \%$ is accompanied with comminuted fracture. They occur due to the force of projectiles from firearms or a piece of grenade, land mines or other explosive devices. The treatment of gunshot fractures of the extremities is never conducted simultaneously. It is most frequently conducted in two continuous phases.

In the first phase, not later than 8 hours after the injury, primary treatment of a gunshot wound is conducted. This is the most important surgical operation, after which the gunshot wound should be "sterile" $(1,2)$. The stabilization of broken bones is about $90 \%$ stabilized with an external fixator and delayed primarily closure of the wound. In the second phase, usually 7 to 10 days after the primary treatment, the war gunshot wound is definitely closed or covered (3).

In the time of the bone tissue processing, it is difficult to estimate the vitality of fragments, as there are no specific indicators for intraoperative assessment of the bone vitality (4). The most common indicators are: bleeding from the exposed ends of the bones, a state of periosteal of bone fragments and the size of bone fragments. After infections, the most serious complications of gunshot injuries of extremities are pseudarthrosis and bone defects whose treatment represents a complex problem in reconstructive surgery. When it comes to the choice of methods for treating these complications, there is no unanimous attitude (2-4). The methods of treatment are: osteoplasty with a cast or external fixator immobilization, osteoplasty and AO plate osteosynthesis and corticotomy and distraction osteogenesis according to Ilizarov.

Grafts and hemotransplants from the bone bank are most commonly used for compensation of bone defects. 
Specialized institutions compensate the bone defect with vascularized grafts, fibula, ribs, radius, iliac, etc. (5).

\section{OBJECTIVE}

The aim was to present the experience and methods gained during the treatment of diaphyseal bone defect as a consequence of gunshot fractures of war trauma. Furthermore, to identify the advantages of one method over another in the treatment of bone defects.

\section{PATIENTS AND METHODS}

The study was retrospective.

Total amount of 2,462 wounded with injuries of the musculoskeletal system were primarily taken care of at the Clinic of Orthopedic and Traumatology in Banja Luka in the period from 1991 to 1995. After the primary treatment of the war wound, external fixator was used in 1573 (64\%) patients. 116 patients with the bone defect were treated at the same time. In order to compensate the bone defect, we used a bone graft and method of bilocal synchronous Ilizarov apparatus for compressive-distraction osteosynthesis. We could not use the bone homotransplants because we did not have the so-called "Bone bank". We also did not use vascularized grafts because we did not have qualified professional team capable of using the above mentioned method. The diagnosis was set on the basis of preoperative radiographic and intraoperative findings during the primary treatment of gunshot fractures. The size of the bone defect was conditioned by the choice of donor sites. The appearance of the wound, swab taken on the eighth day and laboratory findings: erythrocyte sedimentation rate, complete blood count and leukocyte count were the parameters for the assessment of the presence of infection and decision regarding the day of surgical intervention.

The order of work in primary spongioplasty was the following: cleaning and garnishing the operational field of the bone defect and donor sites. Preparation of the spongioplasty anchorage was done as follows: wound was staged, skin firmed and rinsed with up to 8 liters of saline. Wet gauze was placed in the prepared anchorage with a healthy granulation tissue. The gauze was previously soaked in the saline. After that, the prepared place for the autotransplant was covered with dry gauze. Spongious graft up to $1 \mathrm{~cm}^{3}$, that is, cortico-spongious bone according to Phemister, was taken from the selected donor site which was determined by the size of the bone defect.

By applying this method, osteocytes from the grafts were the least exposed to weather and other non-physiological conditions, which may accelerate osteocytes withering from the graft. The bone defect was filled with a sufficient amount of bone grafts and the wound was closed in layers. The bone graft was covered with well vascularized muscle tissue. In cases when the coverage by muscles was not technically feasible, healthy skin was used. Upon the completion of graftation, the donor's site was closed in layers, along with the wound drainage.

On the first postoperative day, a physical therapy and static exercises of the operated limb were done in bed. On the third postoperative day, the patients began to walk with the help of crutches under their armpits, depending on the stability and size of the bone defect. The decision to walk without support, with a touch support or support from 5 to $10 \mathrm{~kg}$ was made on the basis of the size of the defect and the stability of the bone fragments. On the average, the patients were sent to home treatment on the $10^{\text {th }}$ day. Initial controlling radiography was conducted 6 weeks later. Most frequently, the patient or family member (educated at the clinic by the physiotherapist), did kinesitherapy or hydrotherapy at home.

Clinical examinations were carried out every 15 days. The clinical examination monitored the dynamics of the repair of soft tissue and gave an insight into required maintenance around the pins of external fixators.

Radiographic control conducted every 30 days enabled the evaluation of the fracture rehabilitation, assessment of the load degree and the establishment of a full functional use of the extremities. The evaluation of final results was conducted in relation to major complications: nonunion, infection, neurovascular and functional results.

Criteria for the result assessment of the Phemister's spongioplasty good: nonunion, osteomyelitis, neurovascular disturbance, limb-length discrepancy no and joint mobility normal. Result satisfactory nonunion and osteomyelitis no, neurovascular disturbance moderate, joint mobility to $70 \%$, limb-length discrepancy to $3 \mathrm{~cm}$. Poor results: nonunion and osteomyelitis yes, neurovascular disturbance severe, joint mobility under 70\% limb-length discrepancy over $3 \mathrm{~cm}$.

\section{RESULTS}

Early autogenous spongioplasty (primary spongioplasty) was performed for the first time in 1994. It was performed in 18 males with the bone defects that occurred due to projectiles or shrapnel of high initial velocity. The average age was 29.77 (from 19 to 42) years. The primary surgical treatment was performed, on the average, 5.53 hours after the wounding. The average size of the bone defect, formed after the wounding and primary surgical treatment of the war wound was $2.01(4 \mathrm{~cm}-1 \mathrm{~cm}) \mathrm{cm}$. Compensation of bone defect was made 12.22 days after the surgical treatment of the war wound. Earliest compensation of the bone defect was done on the $7^{\text {th }}$ day and not later than 15 days after the primary surgical treatment. The average number of surgeries was 2.2 and the treatment duration was 13.3 months (4-18 months). The external fixator was a final solution in 14 cases, while in 4 cases, re-osteoplastic and AO plates were used. In 5 patients, out of 18, primary graft was taken from both iliac crests. Complications of primary spongioplasty of war wounds were manifested as follows: pseudoarthrosis in 4 patients, transient infections around the pins in 12, joint contractures in 3, and the lower limb-length discrepancy of $2.5 \mathrm{~cm}$ in 2 patients. Neurovascular outbreaks did not occur. (Table 1.)

In our sample 76 patients, that is, $72(95 \%)$ males and 4 (5\%) females, average age $31.79(19-58)$ years, were included in the clinical research of diaphyseal gunshot fractures that had been treated, at the stage of secondary surgery, with AO plate osteosynthesis and the delayed Phemister's spongioplastics. After the primary surgical treatment of the war wound, in 60 (79\%) patients the 
Functional results of primary Phemister's spongioplasty in treatment of 18 patients

\begin{tabular}{lllll}
\hline BONE & GOOD & FAIR & POOR & TOTAL \\
\hline femur & $4(57 \%)$ & $2(29 \%)$ & $1(14 \%)$ & 7 \\
\hline tibia & $1(34 \%)$ & $1(33 \%)$ & $1(33 \%)$ & 3 \\
\hline humerus & $2(66 \%)$ & $1(34 \%)$ & & 3 \\
\hline radius & $1(50 \%)$ & $1(25 \%)$ & $1(25 \%)$ & 3 \\
\hline ulna & & $1(50 \%)$ & $1(50 \%)$ & 2 \\
\hline Total & $8(45 \%)$ & $6(34 \%)$ & $4(21 \%)$ & 18
\end{tabular}

Table 1. Results of primary spongioplasty of war wounds in treatment of 18 patients

above mentioned fractures were stabilized with the external fixator and in 16 (21\%) patients with the plaster splint. The area affected by fractures of the bones was as follows: femur in 28 (37\%) patients, humerus in 19 (25\%), tibia in $9(12 \%)$, both forearm bones in $4(5 \%)$, radius in $11(14 \%)$ and ulna in $5(7 \%)$ patients. The average bone defect was $1.5 \mathrm{~cm}(0.5 \mathrm{~cm}-4 \mathrm{~cm})$.

All patients underwent the first phase of treatment: the wound was closed or covered with high-quality skin; fracture rehabilitation did not occur, nor there were any chances for healing; there was a bone defect to $4 \mathrm{~cm}$ in length and clinical or laboratory signs of infection were not manifested.

After the primary treatment, the war wounds of long bones fragments were stabilized with the external fixators to keep the length of the limbs, quick mobility and proper repair of the soft tissue. There were cases when the intraoperative findings suggested that a proper rehabilitation of the bone would be achieved, but clinical and radiographic findings after 3.6 months on the average (2.1 to 5.8 months) renounced it. Normal general and local examination was usually conducted on the $10^{\text {th }}$ day, after which the secondary surgery compensation of the bone defect was performed using the Phemister's spongioplastics and AO osteosynthesis plate. The average number of surgeries was 3.6 and treatment duration was 32.5 months (9.33-48.83months).

The fracture healing was achieved in 67 (88\%) patients and in $9(12 \%)$ patients a rehabilitation did not occur (Table 2) The latter was managed with re-osteosynthesis . Re-osteosynthesis and re- osteoplastic were conducted in 3 femur bones, 3 tibia bones, 2 ulna bones and 1 humerus bone.

Fibular graft has established itself to be very successful in the treatment of bone defects higher than $5 \mathrm{~cm}$. (Figure 1). Averagely, the fibula is $30 \mathrm{~cm}$ long $3 \mathrm{~cm}$ in diameter,

Functional results of osteosynthesis and AO plate and Phemister's spongioplasty in treatment of 76 patients

\begin{tabular}{lllll}
\hline BONE & GOOD & SATISFACTORY & POOR & TOTAL \\
\hline femur & $16(57 \%)$ & $8(28 \%)$ & $4(15 \%)$ & 28 \\
\hline tibia & $2(18 \%)$ & $4(44 \%)$ & $3(34 \%)$ & 9 \\
\hline humerus & $12(63 \%)$ & $6(32 \%)$ & $1(5 \%)$ & 19 \\
\hline radius & $7(64 \%)$ & $3(27 \%)$ & $1(9 \%)$ & 11 \\
\hline ulna & $1(20 \%)$ & $2(40 \%)$ & $2(40 \%)$ & 5 \\
\hline both bones & $1(25 \%)$ & $1(25 \%)$ & $2(50 \%)$ & 4 \\
\hline Total & $36(41 \%)$ & $24(34 \%)$ & $16(25 \%)$ & 76 \\
\hline
\end{tabular}

Table 2. Table 2. Functional results of osteosynthesis and AO plate and Phemister's spongioplasty in treatment of 76 patients and hence is very suitable for large forearms bone defects. In humerus, femur and tibia defects, it can be placed in the medullary canal as well. Gilbert's modification of the original Taylor's posterior approach is the most suitable method to apply when taking the fibular graft.

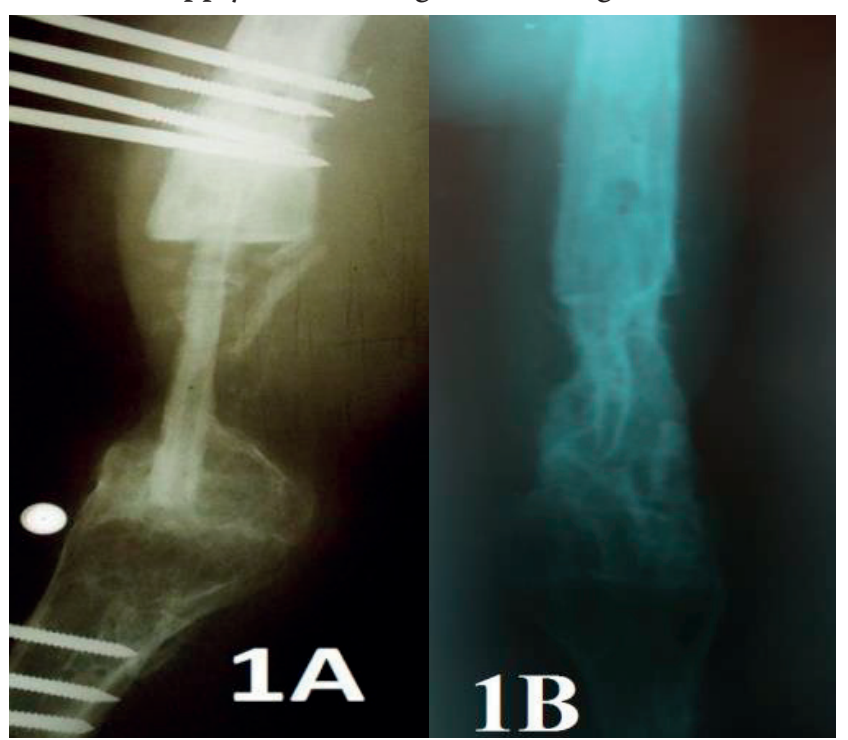

Figure 1a, 1b. Femur defect recovered by the fibular graft

Result after 17 years 8 patients, 7 males and 1 female, average age 29.97 (19-45) years were included in the clinical research of diaphyseal gunshot fractures which had been treated, at the stage of secondary surgery, with fibular graft. After the primary surgical treatment of the war wound, the above mentioned fractures were stabilized with the external fixator. The area affected by fractures of the bones was as follows: femur in 5 patients, humerus in 2 and ulna in 1 patient. The average bone defect was 6.2 $\mathrm{cm}(5-9.6 \mathrm{~cm})$. The average follow-up was 22.5 months (9.3338.32 months). The assessment of the final results was carried out in relation to major complications.

The fracture healing was achieved in 6 patients while in 2 patients the rehabilitation of the bone did not occur. The fibular graft ingrowth was not achieved in 2 patients treated for bone defects in the ulna and humerus. Functional results of bone defects treated with fibular graft are shown in Table 3.

Functional results of bone defects treated with fibular graft- 8 patients

\begin{tabular}{lllll}
\hline BONE & GOOD & FAIR & POOR & TOTAL \\
\hline femur & $2(40 \%)$ & $2(40 \%)$ & $1(20 \%)$ & 5 \\
\hline humerus & $1(50 \%)$ & $1(50 \%)$ & & 2 \\
\hline ulna & & & $1(100 \%)$ & 1 \\
\hline Total & $3(38 \%)$ & $3(38 \%)$ & $2(24 \%)$ & 8
\end{tabular}

Table 3. Functional results of bone defects treated with fibular graftin treatment of 8 patients

Compensation of the tibia bone defect in 14 patients, that is, $12(86 \%)$ males and 2 (14\%) females, average age 30 years (22-42 years), was performed using the Ilizarov technique of extension of one of the fragments in order to reconstruct the tibia bone defect. The average length of the tibia defect was $5.6 \mathrm{~cm}(3.5$ to $8.5 \mathrm{~cm})$. The tibia defects were accompanied with various neurological and vascular damage and injuries of tendons and muscles of 
the lower leg. All patients had a flexion-extension contracture of the knee and / or ankle joint equinus, as well as the significant soft tissue defect due to the initial injury or debridement. Averagely, the rehabilitation was 10 months long (4-17 months). In 10 patients, the average bone defect was $4.7 \mathrm{~cm}$ (3.5 to $6.0 \mathrm{~cm})$, with interfragmentary diastasis of $1.5 \mathrm{~cm}(1-2.5 \mathrm{~cm})$ and anatomical discrepancy of $3.1 \mathrm{~cm}(2,0-5,0 \mathrm{~cm}) . \mathrm{In} 4$ patients with the average length of the defect of $6.4 \mathrm{~cm}(4.0$ to $8.5 \mathrm{~cm})$ and interfragmentary diastasis of $5.5 \mathrm{~cm}(4.5-7.5 \mathrm{~cm})$ and anatomical discrepancy of $1.6 \mathrm{~cm}(1-2 \mathrm{~cm})$, the bilocal alternating distraction and compressive-distraction osteosynthesis was used (Figure 2).

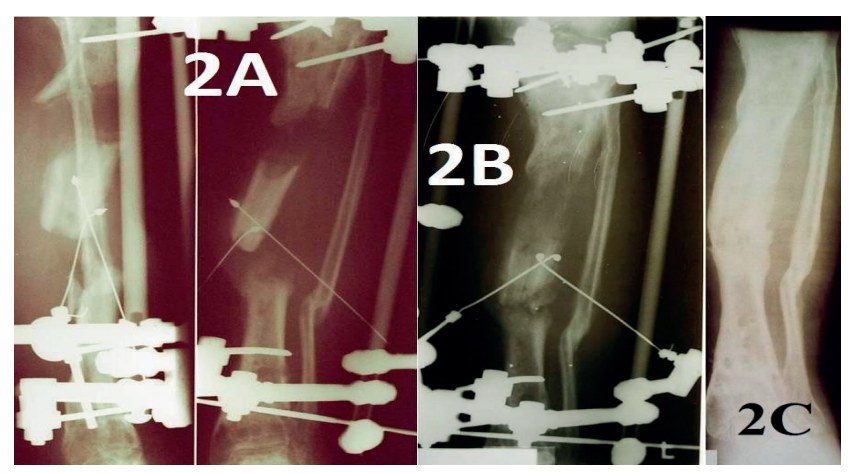

Figure 2a, 2b, 2c. Compensation of bone defect of $7.6 \mathrm{~cm}$ with the usage of distraction osteosynthesis Mitković external fixator, 2A 15 days, 2B 35 days and 2C 14 months after the corticotomy

In 13 patients, the osteotomy was performed in the proximal and in 1 patients in the distal fragment of the tibia. Radiographic evaluation was performed every 2 weeks during the distraction phase and every 4 weeks during the consolidation phase.

We evaluated the results of treatment according to the classification of the Association for the Study and Application of the Ilizarov Method, graded as: excellent, good, fair and poor.

Monitoring of the patients lasted about 32 months (1848 months). During the treatment, the mean distraction index value was 10.6 (10-11), maturation index was 39.8 (36-45), and external fixation index was 52.5 (49 to 57.4). The average duration of wearing the external fixator was 8.5 months (from 6.0 to 12.0 months). The healing of points of contact of the fragments was registered in 11 patients. In 3 patients, there was no healing (pseudoarthrosis was formed) and they underwent the additional surgical treatment, which involved the application of the Ilizarov apparatus for the compression osteosynthesis along with opening and processing of the contact. Upon this surgical intervention, the healing occurred at the point of contact, with extended treatment duration. The average healing of the points of contact of the fragments was 4.6 months (4-5 months). In 3 patients, angular deformity of the tibia of $10^{\circ}$ was established. Postoperative leg length discrepancy did not occur in 3 patients, while 8 patients had the average discrepancy of $1.6 \mathrm{~cm}(1-3 \mathrm{~cm})$. Subsequent surgical correction of the shin length was recommended to 3 patients with the discrepancy of $3 \mathrm{~cm}$, and they rejected it.

On the last medical check-up, we found an infection in 2 patients. In 9 patients, "bone result" was excellent, while it was good in 5 patients. Significant postoperative limping occurred in 6 patients, 4 of them had fixed contractures of the knee and ankle, and 2 of them had atrophy of the shin muscles of mild degree. 8 patients did not complain of pain, while 5 patients reported moderate pain, and only 1 patient suffered from acute pain. Taking these criteria into consideration, the functional outcome was excellent in 8 , good in 3, and fair in 3patients.

A total of 16 complications occurred in 14 patients. The most common complication, which occurred in 8 patients, was inflammation and maceration of soft tissue around the needle. In 1 patient, after the above mentioned treatment, the inflammatory process was not repaired and it extended along with the formation of abscesses. During needle placement in 2 patients, due to termonecrosis of the bone, sequestration ring that was the cause of "osteomyelitis needles"was created. The needles were drawn out and the needle canal expanded and drained which led to remediation of the infection. During the treatment, the acute exacerbation of chronic osteomyelitis occurred in 2 patients, and in 3 patients the wound did not heal and pseudoarthrosis occurred. All 5 patients were subjected to the additional surgical treatment. In the treatment process, dermatitis occurred in 1 patient.

\section{DISCUSSION}

In their study, Atesalpa et al. analyzed the results of treatment of 43 patients with a bone defect. 18 patients with the bone defect had chronic osteomyelitis of the tibia as well. The average length of the defect was $10.1 \mathrm{~cm}(2-15$ $\mathrm{cm}$ ) (6). The average duration of external fixation was 15.8 months. In all cases the treatment was carried out without antibiotic therapy. The authors annotated this with an aggressive debridement of necrotic and infected bone, as well as with the increase of the intramedullary circulation by the osteotomy of one of the fragment of the tibia (6).

In his experimental studies, Albreht discovered that local administration of antibiotics up to three hours after the injury may provide a 72-hours delay of the primary surgical management of the wound without increasing the incidence of local infection. Jackson came to similar conclusion during the Falklands War. Antibiotic therapy was administrated not later than 6 hours after the wounding. 7 The results showed that there were no septic complications when the antibiotics were administered three hours after the wounding, because they inhibited the growth of bacteria in the gunshot wounds (7).

During the treatment of 1.361 patients with gunshot fractures of long bones in Angola, Karapetjen and Petrov adopted the attitude that the internal osteosynthesis can be performed with previous administration of antibiotics. Apart from the above mentioned osteosynthesis, after 21 days the tibial or fibular bone grafting was performed in 17 patients. The result of treatment was satisfactory in 11 patients and poor in 8 (8).

Mironov used the property of spongiosis resistance to infection, and laminated the osteomyelitic defects using the spongiosis parts and leaving the wound open after the lamination. Mironov called this method "the open spongioplastics 89).

On the basis of the experiences in the Afghanistan war regarding the treatment of bone defects, Gricanov et al. 
preferred the external fixators and insisted on compressive and distraction external fixators with hinged joints (10).

Jovanovic submitted criteria for treatment of the bone defect in long bones with autogenous bone grafts and stabilization of bone fragments with the compressive $\mathrm{AO}$ plates (11).

We had the similar experience and results in our study.

\section{CONCLUSION}

The application of early autogenous spongioplasty in bone defects of war wounds proved to be successful and possible in the primary stage of treatment. Rigid osteosynthesis with AO plate along with delayed spongioplstic proved to be very successful in the secondary treatment of large number of samples taken from the above mentioned war. The extension of one of the fragments using the Ilizarov method can successfully compensate for the bone defect of $11.5 \mathrm{~cm}$ and equalize the limb in one act. This method brings the possibility of "unlimited" creation of bone tissue.

\section{CONFLICTS OF INTEREST: NONE DECLARED.}

\section{REFERENCES}

1. Grubor P. Treatment of Bone Defects. SaarbrÜcken, Germany: LAP LAMBERT Academic Publishing GmbH\&Co; 2012.

2. Grubor P, Grubor M, Asotic M. Comparison of Stability of Different types of External Fixation. Med Arch. 2011; 65(3):
157-159.

3. Grubor P, Falzarano G, Medici A, Grubor M, Franzese R, Errico G et al. The Bosnian War: The Damage Control Orthopedics and External Fixation in traffic accident after 20 Years in the Bosnian War: Our Experience and a Review of the Literature“. SYLWAN. 2014; 158(6): 90-109.

4. Grubor P, Faizarano G, Grubor M, Piscopo A, Franzese R, Meccariello L. Tretment of the cronic War tibial osteomyelitis, Gustilo tipe IIIb and cierny IIIb, using various methods. A retrospective study. Euromediterran Biomedical Jurnal. 2014; 9(2): 7-18.

5. Atesalp AS, Basbozkurt M, Erler E, Sehirlioglu A, Tunay S, Solakoglu C, et al. Treatment of tibial bone defects with the Ilizarov circular external fixator in high-velocity gunshot wounds. Int Orthop. 1998; 22(6): 343-347.

6. Albreht M, Šćepanović D. Expermental soft tissue wounds caused by standard military rifles. Acta Chir Scand. 1979; 489: 185-189.

7. Karapetjan S, Petrov V. Taktika hirurgičeskog lečenja ognestrelnih prelomov trubčatih kostej. Ortop Travmat Protez. 1984; 6: 11-14.

8. Mironov G, Nemitin J. Specijalizirovannoe lečenie ranenih s osloženenijami I neblagoprijatnim posledstvijami ognestreljnih ranenij konečnostej. Voenno Med Zh. 1991; 7: 17-18.

9. Coupland R. The role of Reconstructive surgery in the management of War Wounds. Injury. 1994; 25: 211-217.

10. Jovanović Z, Popović Z. Hirurško lečenje strelnih preloma-primarna hirurgija. Zbornik radova kongresa Zsl I SnSl u ratu 1991/92, Banja Luka. 1992: 171-172. 